\title{
Fibre Bragg grating sensors for the analysis of pressure distribution at a disc brake/pad interface
}

\author{
B. T. Major ${ }^{\mathrm{b}}$, D. Tiwari $^{\mathrm{a}}$, R. Correia ${ }^{\# \mathrm{a}}$, S. W. James ${ }^{* \mathrm{a}}$ M. Tirovic ${ }^{\mathrm{b}}$ and R. P. Tatam ${ }^{\mathrm{a}}$ \\ ${ }^{\mathrm{a}}$ Engineering Photonics and ${ }^{\mathrm{b}}$ Advanced Vehicle Engineering Centre, \\ Cranfield University, Bedfordshire MK43 0AL, UK
}

\begin{abstract}
The use of optical fibre Bragg gratings (FBGs) to monitor the Interface Pressure Distribution (IPD) on an automotive disc brake pad under a variety of loading conditions is studied. The results demonstrate successful strain transfer from the brake pads to the attached FBG sensors under static loading, with a linear response to increasing pressure, and with the measured IPD showing good agreement with that recorded using pressure sensitive paper. Results are also presented demonstrating that changes in the IPD as a result of torque acting on the brake pads can be monitored by the FBG sensors.
\end{abstract}

Keywords: Fibre Bragg gratings, brakes, automotive, interface pressure

\section{INTRODUCTION}

In the automotive industry, knowledge of the pressure distribution at the interface between the brake pads and the disc is of critical importance to all aspects of braking performance; wear, reliability, noise, vibration and harshness (NVH) characteristics ${ }^{1}$. With vehicle safety being one of the major concerns for vehicle manufacturers, enhanced knowledge of brake pad characteristics could aid improvements in road safety and reduce maintenance/inspection costs. In addition, monitoring the interface could aid a reduction in the one billion dollar cost of NVH warranty claims ${ }^{2}$.

In recent years, Interface Pressure Distribution (IPD) has been the subject of considerable interest. Studies of IPD have been generally carried out under static loading conditions, as the available measurement approaches, such as Pressure Sensitive Paper (PSP) ${ }^{3}$ and pressure pads ${ }^{4}$ cannot be used if the disc is rotating. In addition their incorporation into the structure can lead to significant changes in the make-up of the brake pad leading to unrepresentative results. FEA simulations can be used to make estimations of the brake pad pressure distributions ${ }^{5}$, showing good agreement with experimental data obtained using PSP, but there is still a requirement for the development of sensors that can be deployed to make dynamic measurements of IPD.

This paper investigates the possibility of using FBGs to allow the pressure distribution at the contact interface of a brake pad to be mapped under static loading conditions and when a torque is applied to the brake disc. In this study, the FBGs do not measure the pressure directly, rather they detect the strain caused by the pressure induced deformation of the pad. For the first time, the ability to monitor changes in the IPD as a result of torque acting on the brake disc is reported, illustrating the potential of the use of FBGs for dynamic measurements of IPD.

\section{EXPERIMENT}

\subsection{Instrumentation}

Four arrays of FBGs, where each FBG had a gauge length of $3 \mathrm{~mm}$ and a peak reflectivity of approximately $30 \%$, were fabricated in single-mode boron-germanium co-doped optical fibres with a cut-off wavelength of $1250 \mathrm{~nm}$ (Fibrecore PS1250). The FBGs had Bragg wavelengths $\left(\lambda_{B}\right)$ in the range 1293.6-1325.2 nm. The interrogator system used a broadband light source and a Fabry-Perot scanning filter ${ }^{6}$. The output signal was recorded using a data acquisition card (DAQ) and processed in a computer with software analysis built in LabView. To facilitate a qualitative analysis of the performance of the FBG sensors, the IPD was also monitored using PSP (Pressurex, Sensor Products Inc).

*s.w.james@cranfield.ac.uk; phone +44 (0) 1234 754623; openoptics.info.

\# current address: Department of Electrical and Electronic Engineering, University of Nottingham, NG7 2RD, UK

\footnotetext{
25th International Conference on Optical Fiber Sensors, edited by Youngjoo Chung, Wei Jin

Byoungho Lee, John Canning, Kentaro Nakamura, Libo Yuan, Proc. of SPIE Vol. 10323,

$1032320 \cdot$ C C 2017 SPIE $\cdot$ CCC code: 0277-786X/17/\$18 - doi: 10.1117/12.2263455

Please refer to any applicable publisher terms of use.

Proc. of SPIE Vol. 10323 103232O-1
} 


\subsection{FBG Installation on brake pad and brake actuation system}

The brake pads that were used for the experiment are part of the HiSpec Monster range. The pads each contain two slots, as shown in figure 1(a), that add flexibility, relieving stresses introduced when the pad is heated, and that allow gasses and debris to escape. Four fibres, each containing an array of three or four FBGs, were attached to the brake pad, two on the inside edges of the pre-machined slots and two on the outside edge of the brake pad (Figure 1 (a)) using a combination of superglue and epoxy resin. This provided good contact between the fibre and brake pad material, while also adding protection for the fibre. The instrumented brake pads were installed into brake calipers (Figure $1 \mathrm{~b}$ ). The calipers were actuated using an air over hydraulic braking system and the air pressure was regulated to obtain the desired hydraulic pressure using the process described in detail elsewhere ${ }^{7}$.

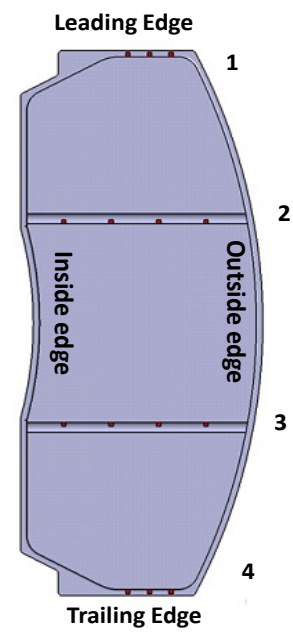

(a)

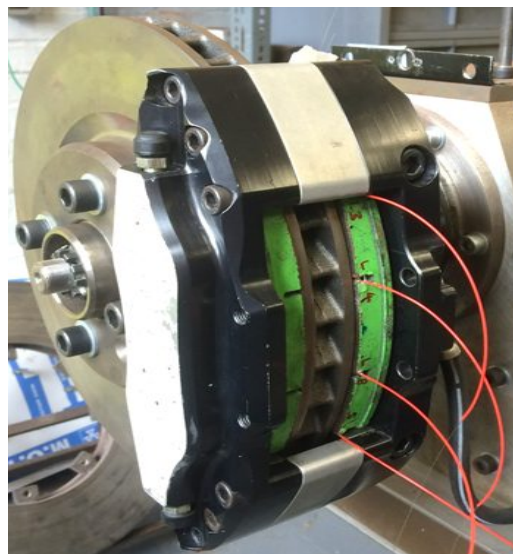

(b)

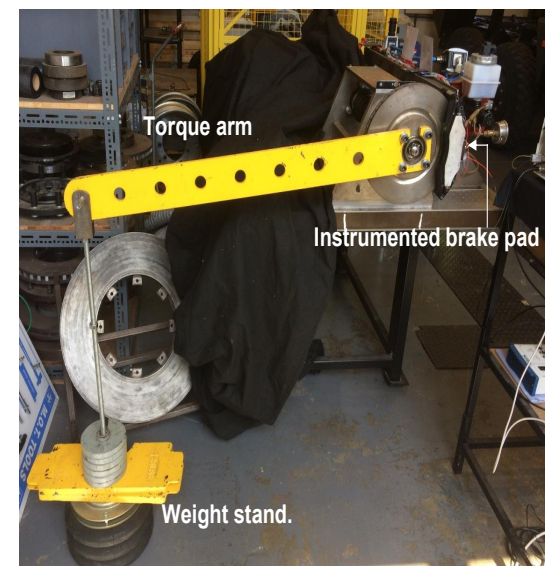

(c)

Figure 1 (a) FBG placement (shown as red dots) on the brake pad (dimensions: length $13.4 \mathrm{~cm}$, width $10.5 \mathrm{~cm}$ and height $1.5 \mathrm{~cm}$ ) (b) Instrumented brake pad within the brake caliper (c) Set-up for torque experiments.

\subsection{Loading experiments}

The hydraulic pressure was increased from 10 bar to 100 bar in 10 bar increments, and the changes in the Bragg wavelengths recorded. The measurements were repeated 3 times. The experiment was also performed using PSP at hydraulic brake actuation pressures of 40,60,80 and 100 bar, and the interface pressure distribution compared qualitatively with the data from the FBGs. For torque measurements, a $1 \mathrm{~m}$ long, 10kg arm was bolted onto the face of the brake disc, as shown in figure 1(c), and weights were attached to the end of the arm.

\section{RESULTS}

\subsection{Static loading}

Typical data obtained during brake actuation is shown in Figure 2 (a), where the wavelength changes exhibited by the 4 FBGs in Fibre 2 are shown. Upon the application of 30 bar hydraulic pressure to the brake (after $20 \mathrm{sec}$ ), an increase in Bragg wavelength shift $\left(\Delta \lambda_{B}\right)$ was observed, corresponding to the FBGs experiencing tensile strain in response to the pressure induced deformation of the pad, which remains constant while the caliper was actuated (for $15 \mathrm{sec}$ ) and returned to original value as brakes are released. This process was repeated three times and the response of the sensors was observed to match the actuation of the caliper. The data shows that the pressure is higher on the inside edge as compared to the outside edge. The responses obtained from FBGs on fibres 1, 3 and 4 showed a similar pattern. Figure 2 (b) shows that the measured $\Delta \lambda_{B}$ exhibited a linear dependence on the applied hydraulic pressure, with a gradient of $0.0025 \mathrm{~nm} / \mathrm{bar}$.

Figure 3 (a) shows the strain measured by the FBG sensors under a static load caused by a hydraulic brake actuation pressure of $80 \mathrm{bar}$. The results indicate that the highest pressures were observed by fibre 3 and the IPD greatly reduces at the FBG closest to the Outer Diameter (OD) of the brake pad. Fibre 2 shows a similar pattern, indicating that higher pressures were observed close to the Inner Diameter (ID) of the brake pad while reducing locally to the FBG located at the OD. The results obtained from FBGs were compared qualitatively against the results obtained from PSP (calibrated 
for pressures between 25-100 bar) under same loading conditions. PSP uses the colour differential from white to red to determine the proportional pressure distribution across a particular area. The results obtained from the PSP (Figure $3 \mathrm{~b}$ ) depict a similar pattern of IPD at the brake pad. The PSP was dark red towards the ID of the brake pad and was completely white towards the OD, thus indicating that FBGs are observing loading in similar areas.
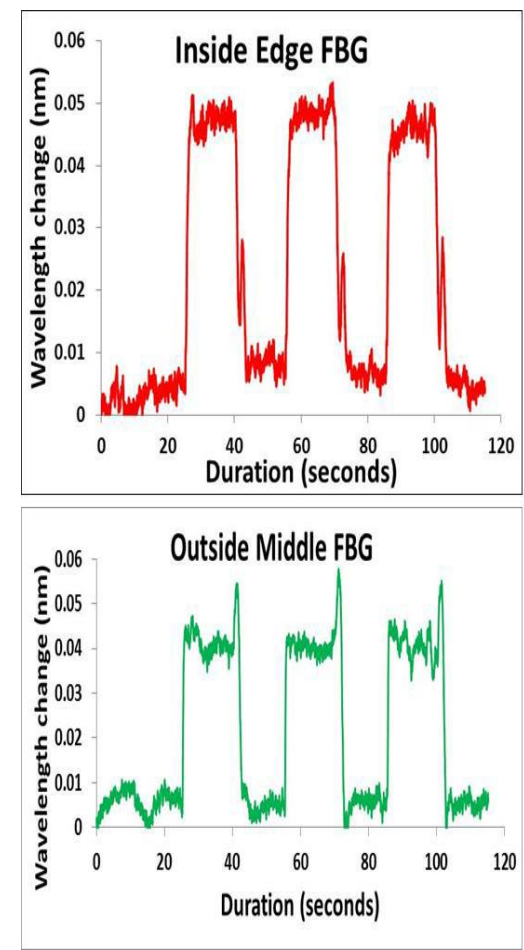

(a)


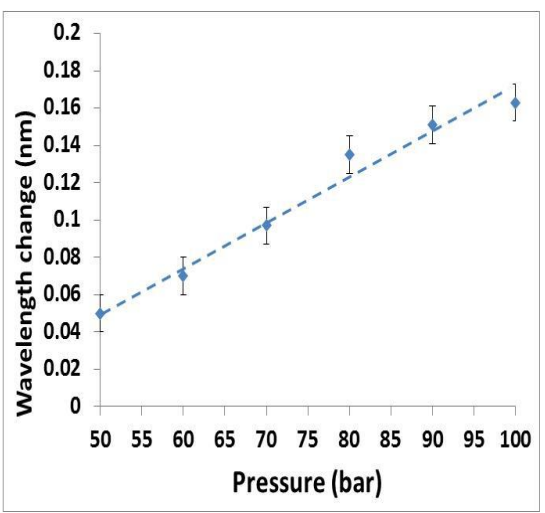

(b)

Figure 2 (a) The changes in Bragg wavelengths of the four FBGs in Fibre 2 measured when a 30 bar hydraulic brake actuation pressure was repeatedly applied to the caliper. (b) Linear relationship between wavelength change and hydraulic brake actuation pressure for FBG closest to the inner diameter of the brake pad on Fibre 3.

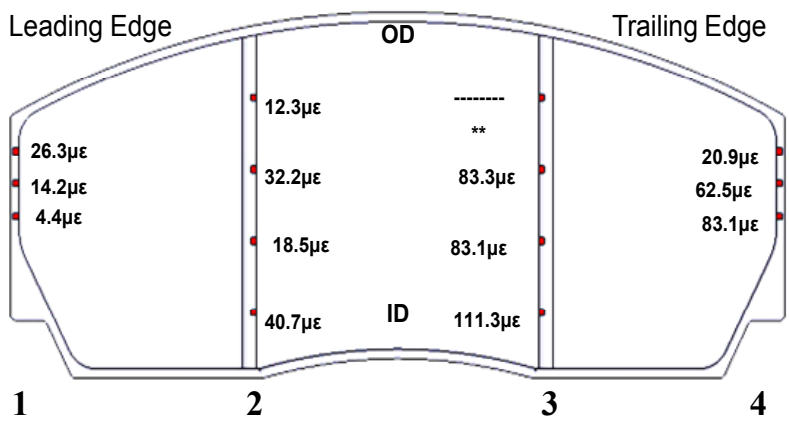

(a)
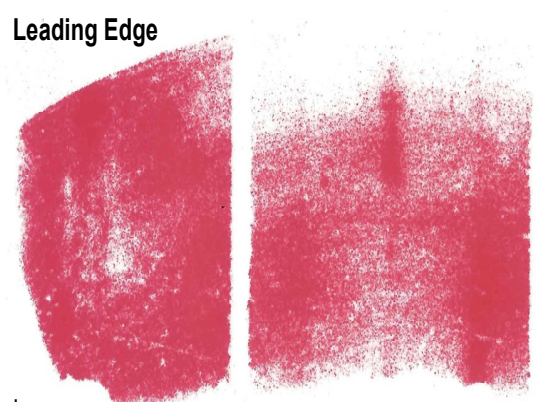

(b)

Figure 3 Comparison between (a) the strain measured by the FBG sensors and (b) the PSP, under static loading with a hydraulic brake actuation pressure of $80 \mathrm{bar}$.

\subsection{Torque loading}

With the torque arm connected to the brake disc and held parallel to the floor, a hydraulic pressure of 40 bar was applied to the brake system. The torque was increased by adding weights to the end of the arm, as described in Section 2.3.

Figure 4 shows the wavelength shifts exhibited by the three FBGs on Fibre 4 as the torque increased. At point "a", the 
torque arm was released, and the shear stress acting on the pad by virtue of the friction between the pad and the disc, caused a decrease in the measured Bragg wavelengths. At points "b", "c" and "d", the torque was increased by adding $10 \mathrm{~kg}$ weights to the end of the arm, with concomitant changes in the Bragg wavelengths. Finally, at "e" a $10 \mathrm{~kg}$ weight was added, leading to a torque of approximately $450 \mathrm{Nm}$ acting on the brake disc. At this point, the torque acting on the brake disc overcame the actuation force on the pads, causing the torque arm to rotate around the drive shaft axis until it came in contact with the ground. This caused the shear stress to relax, and the Bragg wavelengths returned towards the values observed when the caliper was initially activated.

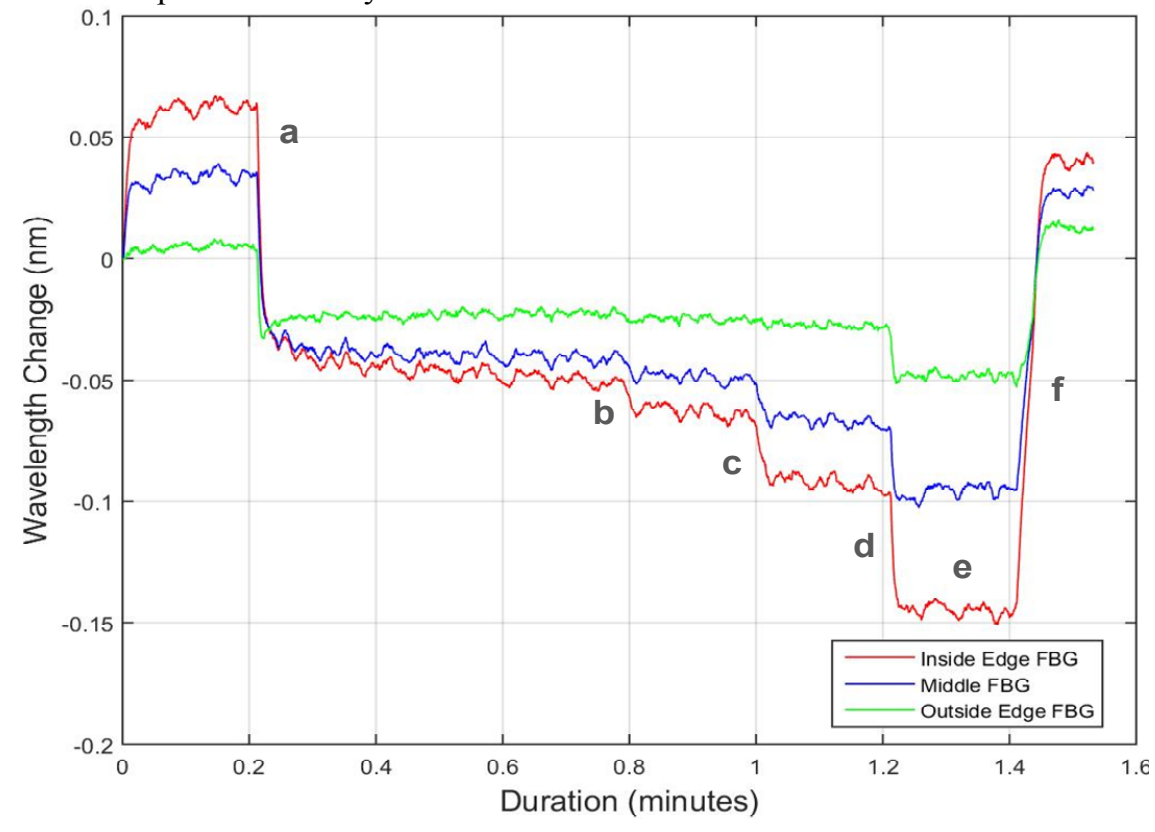

Figure 4. The change in Bragg wavelength of the three FBGs in Fibre 4 when torque was applied to the brake disc.

\section{CONCLUSIONS}

The use of FBGs to provide a measure of the loading at a number of locations on a brake pad during brake actuation has been explored. The FBGs measured the strain induced by the deformation of the pad caused by the applied pressure. These measurements gave an indication of the IPD of the brake pad surface, showing qualitative agreement with results obtained using pressure sensitive paper. When a torque was applied to the brake disk, the FBG sensors indicated a compressive load as the friction between the pad and disc induced shear stress. Future work will explore the use of FBGs in a dynamic braking event, with the brake system mounted on a brake dynamometer and where PSP cannot be used.

\section{REFERENCES}

[1] Tirovic, M., Day, J., “Disc brake interface pressure distributions”, Proc. IMechE. J. Automob. Eng. 205(24), 137$146(1991)$.

[2] Akay, A., "Acoustics of friction", J. Acoust. Soc. Am. 111(4), 1525-1548 (2002).

[3] Tirovic, M., Voller, G. P., "Interface pressure distributions and thermal contact resistance of a bolted joint", Proc. Roy. Soc. A 461, 2339-2354 (2005)

[4] Cristol-Bulthé, A.L., Desplanques. Y., Degallaix. G., "Coupling between friction physical mechanisms and transient thermal phenomena involved in pad-disc contact during railway braking," Wear 263,1230-1242 (2007)

[5] Voveris, J., "Race car brake caliper analysis", Cranfield University, MSc Thesis (2010).

[6] Wei, C.Y., James, S. W., Tatam, R.P., Irving, P. E, "Application issues using fibre Bragg gratings as strain sensors", Strain 36(3), 43-50 (2000).

[7] Major, B., "Disc brake interface pressure distribution measurements", Cranfield University, MSc Thesis (2015). 
2017-04-24

Fibre Bragg grating sensors for the analysis of pressure distribution at a disc brake/pad interface

Major, B. T.

SPIE

B. T. Major, D. Tiwari, R. Correia, S. W. James, M. Tirovic and R. P. Tatam. Fibre Bragg grating sensors for the analysis of pressure distribution at a disc brake/pad interface. 25th International Conference on Optical Fiber Sensors, 24-28 April 207, Jeju, Republic of Korea http://dx.doi.org/10.1117/12.2263455

Downloaded from Cranfield Library Services E-Repository 